Check for updates

Cite this: RSC Adv., 2017, 7, 51678

Received 28th September 2017 Accepted 2nd November 2017

DOI: 10.1039/c7ra10733a

rsc.li/rsc-advances

\section{Formation of oxygenated polycyclic aromatic hydrocarbons by photoelectrocatalysis using $\mathrm{TiO}_{2}$ nanotubes $\dagger$}

\begin{abstract}
Meng Qiao, (D) ${ }^{a}$ Bochuan Liu, ${ }^{a}$ Xu Zhao, ${ }^{* a b}$ Yan Gong, ${ }^{a}$ Yanbin Wang ${ }^{a}$ and Wei Cao ${ }^{a}$
The transformation intermediates of the polycyclic aromatic hydrocarbons (PAHs), including the oxygenated PAHs in photoelectrocatalytic (PEC) processes has seldom been reported. In this study, anthracene (Ant), a typical PAH, was selected as the target compound. The main transformation intermediates including anthranone (AT) and anthraquinone (AQ) were analyzed in a PEC process using $\mathrm{TiO}_{2}$ nanotubes (TNTs) as a photoanode with simulated solar light irradiation and a bias potential. AT and $A Q$ were demonstrated to be formed from Ant in the PEC process. However, the elimination of AT and $A Q$ was hardly observed when Ant was mostly eliminated. The PEC process efficiently enhanced the elimination of Ant, as well as the total molar concentration of Ant, AT and AQ, compared with the photocatalysis and electrochemical oxidation process. The PEC process achieved a best elimination efficiency at $1.0 \mathrm{~V}$ bias and $\mathrm{pH}$ 2.0. The elimination efficiency decreased with the increase of the Ant initial concentration. The effect of humic acid was explored. It was concluded that the ${ }^{\cdot} \mathrm{O}_{2}{ }^{-}$radical was more effective than ${ }^{\circ} \mathrm{OH}$ for the transformation of Ant to AT and AQ. Furthermore, compared with the UV light photocatalysis (PC), the PEC process could save much energy in the aspect of Ant elimination.
\end{abstract}

\section{Introduction}

Polycyclic aromatic hydrocarbons (PAHs) and their transformation intermediates (SPAHs) are ubiquitous in the water environment. In the chemical treatment process, before they are totally degraded, PAHs could be transformed to their intermediates. ${ }^{1}$ Typical SPAHs have been detected in urban rivers and wastewater treatment plants. ${ }^{2,3}$ Some of the SPAHs are as toxic as or more toxic than their corresponding PAHs. Therefore, the transformation intermediates should be taken into consideration in studying the PAH elimination. During the photocatalytic oxidation process of PAHs, oxygenated PAHs (OPAHs) were the main intermediates., ${ }^{\mathbf{1 , 4 5}}$

Photocatalysis is an attractive method for water purification due to its low cost and non-addition of chemical reagents. ${ }^{4}$ Titanium dioxide $\left(\mathrm{TiO}_{2}\right)$ has received much attention as an effective material for photocatalysis. However, $\mathrm{TiO}_{2}$ could only be excited by a light wavelength of less than $387.5 \mathrm{~nm}$ (UV light). UV light is an energy consuming technique. Solar light could emit 5\% UV light. If the solar light combined with $\mathrm{TiO}_{2}$ could be used for elimination of contaminants, energy might be

${ }^{a}$ Key Laboratory of Drinking Water Science and Technology, Research Center for Eco-Environmental Sciences, Chinese Academy of Sciences, Beijing 100085, China. E-mail: zhaoxu@rcees.ac.cn; Tel: +861062849667

${ }^{b}$ University of Chinese Academy of Sciences, Beijing 100049, China

$\dagger$ Electronic supplementary information (ESI) available. See DOI: 10.1039/c7ra10733a effectively saved. ${ }^{6}$ In recent years, the photoelectrocatalytic (PEC) process has been widely used, such as the splitting water into hydrogen and oxygen. ${ }^{7}$ There were also studies on the modification of the present electrode to improve the visible light activity. ${ }^{\mathbf{8} 9}$ The PEC process, applying a small positive potential across the photocatalytic anode to enhance the separation efficiency of photogenerated holes and electrons, has been proved to be more efficient for the elimination of pollutants than photocatalytic process. ${ }^{\mathbf{1 0 - 1 2}}$ Meanwhile, the semiconductor electrode could overcome the separation problem of catalyst particles from the treated water. ${ }^{4}$

The reaction process in the $\mathrm{TiO}_{2}$ PEC system was reported as follows: $:^{13,14}$

Anode (working electrode):

$$
\begin{gathered}
\mathrm{TiO}_{2}+h v \rightarrow \mathrm{TiO}_{2}\left(\mathrm{e}_{\mathrm{cb}}^{-}+\mathrm{h}_{\mathrm{vb}}^{+}\right) \\
\mathrm{TiO}_{2}\left(\mathrm{~h}_{\mathrm{vb}}^{+}\right)+\mathrm{H}_{2} \mathrm{O} \rightarrow \mathrm{TiO}_{2}+\mathrm{H}^{+}+\cdot \mathrm{OH} \\
\mathrm{TiO}_{2}\left(\mathrm{~h}_{\mathrm{vb}}{ }^{+}\right)+\mathrm{OH}^{-} \rightarrow \mathrm{TiO}_{2}+\cdot \mathrm{OH} \\
\mathrm{TiO}_{2}\left(\mathrm{e}_{\mathrm{cb}}^{-}\right)+\mathrm{O}_{2} \rightarrow \mathrm{TiO}_{2}+\cdot \mathrm{O}_{2}^{-} \\
\mathrm{O}_{2}^{-}+\mathrm{H}^{+} \rightarrow \mathrm{HO}_{2} \cdot
\end{gathered}
$$

Cathode (counter electrode):

$$
2 \mathrm{H}_{2} \mathrm{O}+2 \mathrm{e}^{-} \rightarrow \mathrm{H}_{2}+2 \mathrm{OH}^{-}
$$


One-dimensional highly ordered $\mathrm{TiO}_{2}$ nanotube (TNTs) electrode has been considered as a promising photoanode for solar energy conversion. ${ }^{15}$ Compared with the $\mathrm{TiO}_{2}$ film electrode, the TNTs electrode was more efficiency for the elimination of organic contaminants. ${ }^{16,17}$ The surface area of the highly ordered TNTs was much larger than $\mathrm{TiO}_{2}$ film or nanoparticles, which was more efficient for electron transport. ${ }^{18}$ In our previous study, TNTs have been electrochemically anodized on the photoanode used for $\mathrm{Cu}$-cyanides and $\mathrm{Cu}$-EDTA degradation. ${ }^{19}$ PEC process with TNTs anode could also be used for synergistically eliminating organic contaminants and heavy metals. ${ }^{6}$ However, the transformation intermediates of the target organic contaminants in the PEC process have little reported.

In this study, anthracene (Ant) was selected as a target PAH compound. The generation of its main transformation intermediates, anthranone (AT) and anthraquinone (AQ) were investigated in details. TNTs electrode with an application of a bias potential under simulated solar light irradiation was used for the elimination of Ant in water environment. The concentrations of AT and AQ were measured during the elimination of Ant under different conditions. Additionally, the energy consumption was compared with the technique of $\mathrm{TiO}_{2}$ combined with UV light.

\section{Materials and methods}

\subsection{Materials}

Chemicals used for TNTs electrode preparation, including hydrofluoric acid $(\mathrm{HF})$, nitric acid $\left(\mathrm{HNO}_{3}\right)$, ammonia sulfate $\left[\left(\mathrm{NH}_{4}\right)_{2} \mathrm{SO}_{4}\right]$, ammonia fluoride $\left(\mathrm{NH}_{4} \mathrm{~F}\right)$, glycerol, acetone and sodium sulfate $\left(\mathrm{Na}_{2} \mathrm{SO}_{4}\right)$, were all analytical reagent grade and purchased from Sinopharm Chemical Reagent Co., Ltd. Chemicals used for Ant, AT and AQ detection, including hexane (HEX), dichloromethane (DCM), methanol (MeOH) and acetonitrile (ACN) were HPLC grade solvents and purchased from Fisher Scientific (USA). Ant $\left(200 \mu \mathrm{g} \mathrm{mL}^{-1}\right.$ in $\left.\mathrm{MeOH}\right)$, AT (solid, analytical standard) and AQ $\left(100 \mu \mathrm{g} \mathrm{mL}^{-1}\right.$ in ACN) were obtained from AccuStandard, Inc. (USA). Internal standards including 2-fluorobiphenyl (2-FB, in solid $>96 \%$ ) and decachlorobiphenyl (PCB209) were obtained from Aldrich Chemical Co., Inc. (Gillingham, Dorset, UK). Analytical grade anhydrous sodium sulfate (Tianjin, China) was baked at $450{ }^{\circ} \mathrm{C}$ for $5 \mathrm{~h}$ before use. The preparation of the TNTs is detailed in Text S1. $\dagger$

\subsection{Photoelectrochemical experiment}

The PEC degradation experiments were performed using three electrodes system in a quartz reactor $\left(70 \times 70 \times 60 \mathrm{~mm}^{3}\right)$. The reactor contained $200 \mathrm{~mL}$ sample solution. The three electrodes included a working electrode (TNTs electrode with an active area of $18 \mathrm{~cm}^{2}$ ), a counter electrode (titanium plate with the same area) and a reference electrode (saturated calomel electrode, SCE). The light source was provided by using a $150 \mathrm{~W}$ Xe lamp (PLS-SXE300; Beijing Perfect Light Co., Ltd, China) without cutoff filter. The power was provided by an electrochemical workstation (Shanghai Chen Hua CHI 660E, China).
In comparison, the photocatalysis (PC), direct photolysis (DP) and electrochemical oxidation (EO) experiments were carried out in the same reactor as the PEC experiment. The PC experiments were performed with the Xe lamp and the TNTs electrode without the power. The DP experiments were performed only with the Xe lamp, and without electrodes or power. The EO experiment was performed with the TNTs electrode combined with the counter and reference electrodes adding the power in darkness.

A certain amount of Ant stock solution $\left(200 \mathrm{mg} \mathrm{L}^{-1}\right.$ in $\left.\mathrm{ACN}\right)$ was added in $200 \mathrm{~mL}$ of ultrapure water to prepare a reaction solution. $1 \mathrm{mM} \mathrm{Na}_{2} \mathrm{SO}_{4}$ was used as the supporting electrolyte. The solution was kept in dark to equilibrium before adding the bias and light. $2 \mathrm{~mL}$ samples were collected at $0,10,20,30$ and $60 \mathrm{~min}$ and extracted by C18 cartridges (Supelco, USA) as soon as possible.

C18 cartridges were activated with $5 \mathrm{~mL}$ DCM, $5 \mathrm{~mL} \mathrm{MeOH}$ and $5 \mathrm{~mL}$ ultrapure water successively before extraction. Then the water samples passed through the cartridges at a rate of $10 \mathrm{~mL} \mathrm{~min}^{-1}$. After the extraction, the cartridges were vacuumed for $20 \mathrm{~min}$. Then the cartridges were eluted with $10 \mathrm{~mL}$ DCM and $5 \mathrm{~mL}$ HEX successively. The eluent passed through anhydrous sodium sulfate to eliminate water. Finally, the eluent was concentrated to $0.5 \mathrm{~mL}$ under nitrogen and the internal standards were added.

\subsection{Analytical method}

Ant, AQ and AT were detected by gas chromatography-mass spectrometry (GC-MS: 7890A GC-5975C MS, Agilent Technologies, USA) with a HP-5MS column $(30 \mathrm{~m} \times 0.25 \mathrm{~mm} \times 0.25 \mathrm{~m})$. The injector and source temperatures were kept at $280{ }^{\circ} \mathrm{C}$ and $300{ }^{\circ} \mathrm{C}$, respectively. The temperature program for Ant was as follows: initial temperature at $80^{\circ} \mathrm{C}$ (held for $1 \mathrm{~min}$ ), increasing to $200{ }^{\circ} \mathrm{C}$ at a rate of $20{ }^{\circ} \mathrm{C} \mathrm{min}{ }^{-1}$, and to $300{ }^{\circ} \mathrm{C}$ at a rate of $10{ }^{\circ} \mathrm{C} \mathrm{min}^{-1}$ (held for $5 \mathrm{~min}$ ).

The radicals during the reaction were measured using an electron spin resonance (ESR) technique. The experiment was conducted on a Bruker A300-10/12 (Germany) instrument using DMPO as the trapping agent. The measurements were conducted using Microwave Bridge (microwave frequency, $9.85 \mathrm{GHz}$; modulation frequency, $100 \mathrm{kHz}$; microwave power, $22.8 \mathrm{~mW}$; modulation amplitude, $1 \mathrm{G})$.

The characterization method for the TNTs electrode is detailed in Text $\mathrm{S} 2 . \dagger$

\section{Results and discussion}

\subsection{Elimination of Ant and formation of $\mathrm{AT}$ and $\mathrm{AQ}$ in the PEC process}

The elimination efficiencies of Ant and the total molar concentration of Ant after oxidation and the formed intermediates AT and AQ (Ant + AT + AQ) during the PEC were compared with the PC, DP and EO process (Fig. 1). The initial concentration of Ant was $125 \mu \mathrm{g} \mathrm{L}{ }^{-1}$ in ultra-pure water at a constant bias potential of $1.0 \mathrm{~V}$ and an initial $\mathrm{pH}$ value of 8.5 . The $\mathrm{pH}$ was not adjusted, and maintained at 8.5 , possibly due to the weakly 

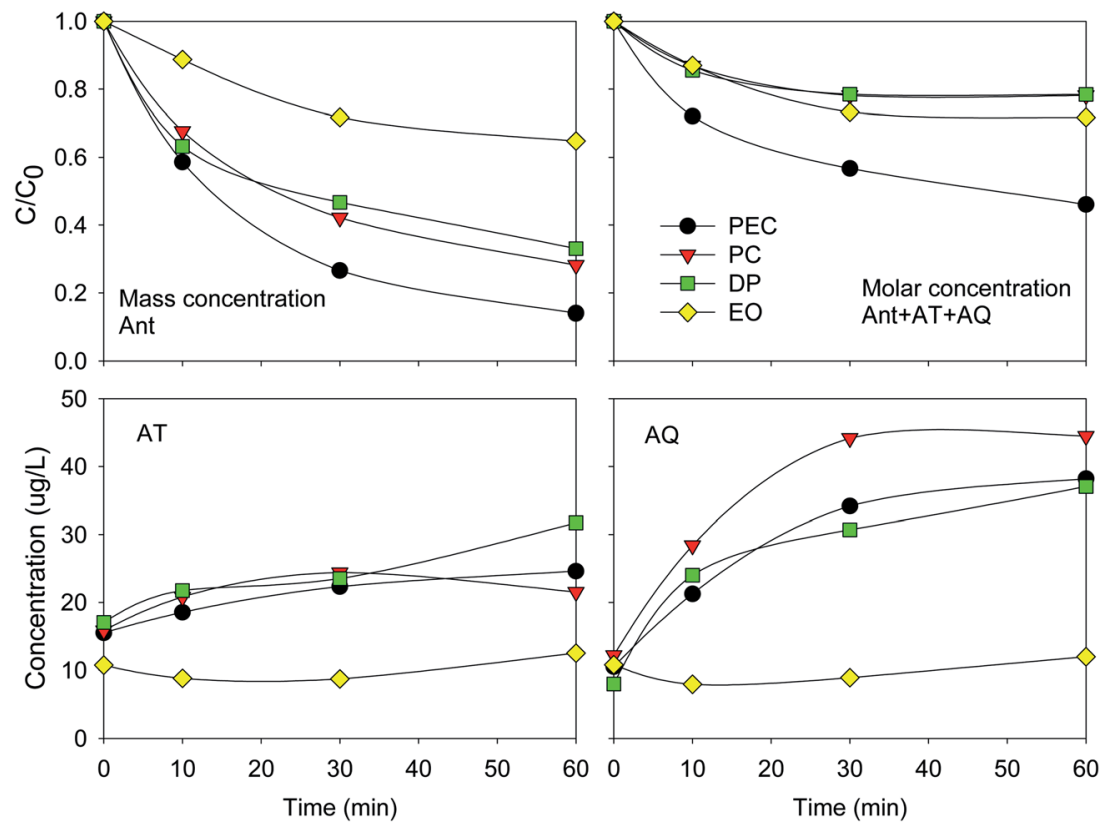

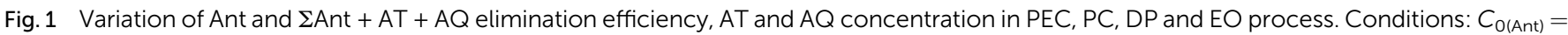
$125 \mu \mathrm{g} \mathrm{L}^{-1}$ in UPW; $E=1.0 \mathrm{~V} ; \mathrm{pH}=8.5$.

alkaline of the ACN aqueous solution. The $\mathrm{TiO}_{2}$ nanotubes characterization and photochemical performance are shown in Text S3 and Fig. S1.†

The eliminations of Ant and Ant $+\mathrm{AT}+\mathrm{AQ}$ almost achieved a balance at $60 \mathrm{~min}$. The final elimination efficiencies of Ant were $35 \%, 67 \%, 72 \%$ and $86 \%$ during the EO, DP, PC and PEC process, respectively. The elimination process of Ant was fitted by the pseudo-first order kinetics:

$$
-\frac{\mathrm{d}[\mathrm{PAH}]}{\mathrm{d} t}=k[\mathrm{PAH}] \Rightarrow \ln \frac{[\mathrm{PAH}]}{\left[\mathrm{PAH}_{0}\right]}=-k \times t
$$

where $k$ is the reaction rate constant, $\left[\mathrm{PAH}_{0}\right]$ is the initial concentration of Ant and $[\mathrm{PAH}]$ is the concentration of Ant at a certain time. The $k$ values and the correlation efficiencies $\left(r^{2}\right)$ were computed and listed in Table 1 . Generally speaking, the elimination of Ant fitted well with the pseudo-first order kinetics, but Ant + At + AQ did not fit well. $K$ of Ant also followed the same order as the final elimination efficiency, EO $\left(0.0077 \mathrm{~min}^{-1}\right)<$ DP $\left(0.0212 \mathrm{~min}^{-1}\right)<$ PC $\left(0.0249 \mathrm{~min}^{-1}\right)<$ PEC $\left(0.0433 \mathrm{~min}^{-1}\right)$ (Table 1). The results showed that the PEC process was more efficient than the EO, DP and PC process for the elimination of Ant, indicating a PEC synergistic effect during the process. The positive bias applied was greater than the flat-band potential of the $\mathrm{TiO}_{2}$ electrode, resulting in the enhancement of the degradation. ${ }^{14}$

Regarding Ant $+\mathrm{AT}+\mathrm{AQ}$, the final elimination efficiencies were $28 \%, 22 \%, 22 \%$ and $54 \%$ during the EO, DP, PC and PEC process, respectively. During the EO process, the concentrations of $\mathrm{AT}$ and $\mathrm{AQ}$ were much lower than those during the $\mathrm{DP}, \mathrm{PC}$ and PEC process. Therefore, though the elimination efficiency of Ant in the DP and PC process was higher than that in the EO process, the elimination efficiency of Ant $+\mathrm{AT}+\mathrm{AQ}$ in the DP and PC process was only a little higher than that in the EO process. Additionally, the elimination of AT and AQ in all the processes could not be observed within the $60 \mathrm{~min}$. Therefore, the transformation intermediates should be considered besides the target compound itself. The concentrations of AT and AQ were moderate in the PEC process, possibly because the AT and $\mathrm{AQ}$ were more easily eliminated in the PEC process than the other process. For another reason, Ant might transform to other intermediates. As a result, from the aspect of transformation intermediates, PEC was also more efficient than PC, DP and EO process.

\subsection{Factors influencing the elimination of Ant and formation of AT and AQ by PEC}

3.2.1 Bias potential effect. The eliminations of Ant were performed under different bias potentials, ranging from 0 to 2.0 V (Fig. 2). The initial concentration of Ant was $125 \mu \mathrm{g} \mathrm{L}^{-1}$ in ultra-pure water at an initial $\mathrm{pH}$ of 8.5. The final elimination efficiencies of Ant in 60 min were the highest at $1.0 \mathrm{~V}(86 \%)$ than other bias potential conditions (72-81\%). The reaction rate constant $k$ of Ant was also the highest at $1.0 \mathrm{~V}\left(0.0433 \mathrm{~min}^{-1}\right)$. While under other bias conditions, the $k$ values were a little lower, ranging from 0.0236 to $0.0351 \mathrm{~min}^{-1}$ (Table 1). Similar result was obtained in the $\mathrm{PEC}$ ( $\mathrm{TiO}_{2}$ electrode) degradation of 4-chlorophenol. ${ }^{17}$ The increasing elimination efficiencies of Ant from 0 to $1.0 \mathrm{~V}$ were probably because the enhanced bias would decrease the recombination of the photogenerated holes and electrons. ${ }^{20}$ Due to the certain thickness of TNTs, the number of photogenerated electrons would be limited by the fixed light intensity. Therefore, at a certain bias value, the elimination efficiency in the PEC process would not improve. Furthermore, the elimination efficiency gradually decreased when the bias 
Table 1 Elimination efficiency of Ant and $\Sigma$ Ant $+\mathrm{AT}+\mathrm{AQ}$ under varies conditions ${ }^{a}$

\begin{tabular}{|c|c|c|c|c|c|c|c|c|}
\hline Variation & Analyte & Condition & $E(\mathrm{~V})$ & $C_{0}\left(\mu \mathrm{g} \mathrm{L}^{-1}\right)$ & $\mathrm{pH}$ & $k\left(\min ^{-1}\right)$ & $r^{2}$ & $E(\%)$ \\
\hline \multirow[t]{8}{*}{ Condition } & Ant & EO & 0 & 125 & 8.5 & 0.0077 & 0.9334 & 35 \\
\hline & Ant & DP & 0 & 125 & 8.5 & 0.0212 & 0.9016 & 67 \\
\hline & Ant & $\mathrm{PC}$ & 0 & 125 & 8.5 & 0.0249 & 0.9595 & 72 \\
\hline & Ant & PEC & 1.0 & 125 & 8.5 & 0.0433 & 0.9833 & 86 \\
\hline & $\mathrm{Ant}+\mathrm{AT}+\mathrm{AQ}$ & EO & 0 & 125 & 8.5 & 0.0058 & 0.8166 & 28 \\
\hline & $\mathrm{Ant}+\mathrm{AT}+\mathrm{AQ}$ & DP & 0 & 125 & 8.5 & 0.0040 & 0.7115 & 22 \\
\hline & $\mathrm{Ant}+\mathrm{AT}+\mathrm{AQ}$ & $\mathrm{PC}$ & 0 & 125 & 8.5 & 0.0040 & 0.7115 & 22 \\
\hline & $\mathrm{Ant}+\mathrm{AT}+\mathrm{AQ}$ & PEC & 1.0 & 125 & 8.5 & 0.0140 & 0.8905 & 54 \\
\hline \multirow[t]{10}{*}{$E$} & Ant & PEC & 0.2 & 125 & 8.5 & 0.0236 & 0.9602 & 72 \\
\hline & Ant & PEC & 0.5 & 125 & 8.5 & 0.0292 & 0.9541 & 78 \\
\hline & Ant & PEC & 1.0 & 125 & 8.5 & 0.0433 & 0.9833 & 86 \\
\hline & Ant & PEC & 1.5 & 125 & 8.5 & 0.0351 & 0.9803 & 82 \\
\hline & Ant & PEC & 2.0 & 125 & 8.5 & 0.0345 & 0.9742 & 81 \\
\hline & $\mathrm{Ant}+\mathrm{AT}+\mathrm{AQ}$ & PEC & 0.2 & 125 & 8.5 & 0.0095 & 0.9716 & 44 \\
\hline & $\mathrm{Ant}+\mathrm{AT}+\mathrm{AQ}$ & PEC & 0.5 & 125 & 8.5 & 0.0128 & 0.9812 & 52 \\
\hline & $\mathrm{Ant}+\mathrm{AT}+\mathrm{AQ}$ & PEC & 1.0 & 125 & 8.5 & 0.0140 & 0.8905 & 54 \\
\hline & $\mathrm{Ant}+\mathrm{AT}+\mathrm{AQ}$ & PEC & 1.5 & 125 & 8.5 & 0.0126 & 0.9702 & 52 \\
\hline & $\mathrm{Ant}+\mathrm{AT}+\mathrm{AQ}$ & PEC & 2.0 & 125 & 8.5 & 0.0095 & 0.9457 & 44 \\
\hline \multirow[t]{10}{*}{$\mathrm{pH}$} & Ant & PEC & 1.0 & 125 & 2.0 & 0.2097 & 0.9987 & 98 \\
\hline & Ant & PEC & 1.0 & 125 & 3.0 & 0.1003 & 0.9958 & 97 \\
\hline & Ant & PEC & 1.0 & 125 & 4.0 & 0.0635 & 0.991 & 92 \\
\hline & Ant & PEC & 1.0 & 125 & 6.0 & 0.0508 & 0.9885 & 92 \\
\hline & Ant & $\mathrm{PEC}$ & 1.0 & 125 & 8.5 & 0.0433 & 0.9833 & 86 \\
\hline & Ant & PEC & 1.0 & 125 & 9.0 & 0.0495 & 0.9548 & 90 \\
\hline & Ant & PEC & 1.0 & 125 & 12.0 & 0.0497 & 0.9695 & 90 \\
\hline & $\mathrm{Ant}+\mathrm{AT}+\mathrm{AQ}$ & PEC & 1.0 & 125 & 2 & - & - & 63 \\
\hline & $\mathrm{Ant}+\mathrm{AT}+\mathrm{AQ}$ & PEC & 1.0 & 125 & 8.5 & 0.0140 & 0.8905 & 54 \\
\hline & $\mathrm{Ant}+\mathrm{AT}+\mathrm{AQ}$ & PEC & 1.0 & 125 & 12.0 & - & - & 48 \\
\hline \multirow[t]{8}{*}{$C_{0}$} & Ant & PEC & 1.0 & 25 & 2.0 & 0.3516 & 0.9993 & 99 \\
\hline & Ant & PEC & 1.0 & 125 & 2.0 & 0.2097 & 0.9985 & 98 \\
\hline & Ant & PEC & 1.0 & 250 & 2.0 & 0.1363 & 0.9968 & 97 \\
\hline & Ant & PEC & 1.0 & 500 & 2.0 & 0.0869 & 1.0000 & 99 \\
\hline & $\mathrm{Ant}+\mathrm{AT}+\mathrm{AQ}$ & PEC & 1.0 & 25 & 2.0 & 0.0338 & 0.9936 & 85 \\
\hline & $\mathrm{Ant}+\mathrm{AT}+\mathrm{AQ}$ & PEC & 1.0 & 125 & 2.0 & 0.0140 & 0.8905 & 54 \\
\hline & $\mathrm{Ant}+\mathrm{AT}+\mathrm{AQ}$ & PEC & 1.0 & 250 & 2.0 & 0.0069 & 0.9160 & 35 \\
\hline & $\mathrm{Ant}+\mathrm{AT}+\mathrm{AQ}$ & PEC & 1.0 & 500 & 2.0 & 0.0061 & 0.7651 & 34 \\
\hline
\end{tabular}

${ }^{a} E$ : bias potential, $C_{0}$ : initial concentration, $k$ : reaction constant, $r^{2}$ : correlation coefficient, $E$ : elimination efficiency.

was greater than $1.0 \mathrm{~V}$. The concentrations of the formed AT, especially AQ increased with the increasing of the bias potential as shown in Fig. 2. Thus, the elimination of the formed intermediates, including AT and AQ, might compete with Ant in the PEC process, resulting to a decreasing elimination efficiencies of Ant from 1.0 to $2.0 \mathrm{~V}^{21}$
Regarding Ant $+\mathrm{AT}+\mathrm{AQ}$, the highest elimination efficiency $(54 \%)$ and $k$ value $\left(0.014 \mathrm{~min}^{-1}\right)$ were also obtained at $1.0 \mathrm{~V}$. Similarly, the elimination efficiencies increased from 0 to $1.0 \mathrm{~V}$, and decreased from 1.0 to $2.0 \mathrm{~V}$. The mechanism was probably the same as indicated above.

3.2.2 $\mathbf{p H}$ effect. The influence of $\mathrm{pH}$ was investigated. The initial concentration of Ant was $125 \mu \mathrm{g} \mathrm{L}^{-1}$ in ultra-pure water at 

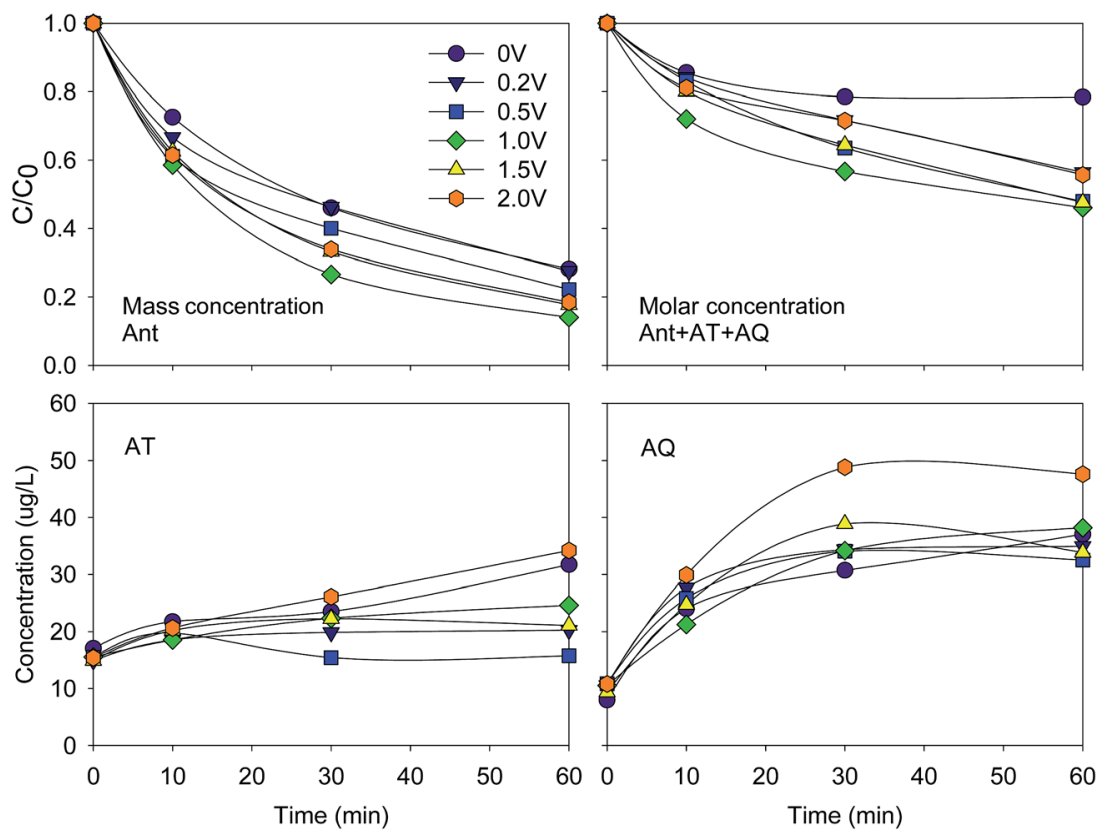

Fig. 2 Variation of Ant and $\Sigma A n t+A T+A Q$ elimination efficiency, $A T$ and $A Q$ concentration at different bias potentials. Conditions: $C_{0 \text { (Ant) }}=125 \mu \mathrm{L} \mathrm{L}^{-1}$ in UPW; $\mathrm{pH}=8.5$
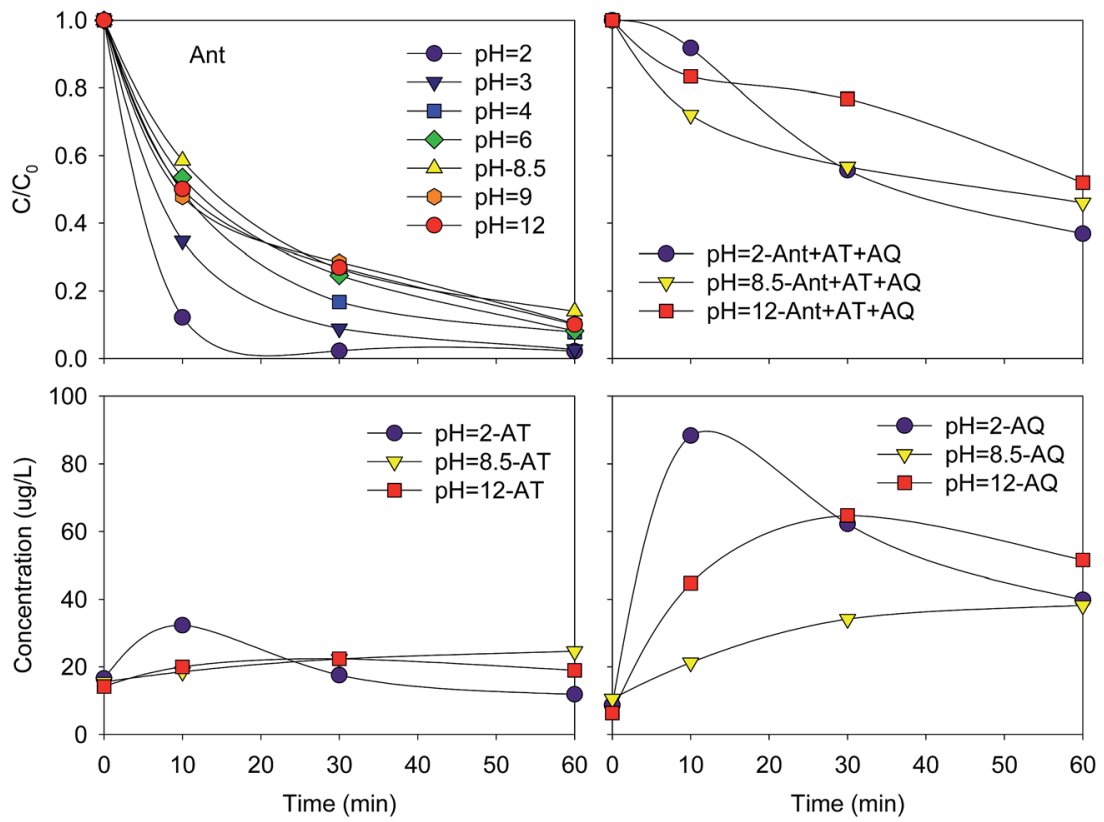

Fig. 3 Variation of Ant and $\Sigma A n t+A T+A Q$ elimination efficiency, $A T$ and $A Q$ concentration at different $p H$ values. Conditions: $C_{0}(A n t)=125 \mu g L^{-1}$ in UPW; $E=1.0 \mathrm{~V}$.

a constant bias potential of $1.0 \mathrm{~V}$. The elimination efficiency and rate of Ant were the highest at $\mathrm{pH} 2.0$, and decreased with the $\mathrm{pH}$ increased up to $6.0\left(E=98-92 \%, k=0.2097-0.0508 \mathrm{~min}^{-1}\right)$ (Fig. 3 and Table 1). The elimination efficiency was $98 \%$ at $30 \mathrm{~min}$ at $\mathrm{pH}$ 2.0. At $\mathrm{pH}$ values ranging from 6.0 to 12.0, the elimination efficiencies and the rate constants did not vary $\operatorname{much}\left(E=86-90 \%, k=0.0433-0.0497 \mathrm{~min}^{-1}\right)$. The point of zero charge value $\left(\mathrm{pH}_{\mathrm{pzc}}\right)$ is the $\mathrm{pH}$ value at which the positive charge number equals to the negative charge number on the surface site. According to the literatures, the $\mathrm{pH}_{\mathrm{pzc}}$ of anatase $\mathrm{TiO}_{2}$ is around 6..$^{22-24}$ The reactions when $\mathrm{pH}<\mathrm{pH}_{\mathrm{pzc}}$ and $\mathrm{pH}>\mathrm{pH}_{\mathrm{pzc}}$ are listed as follows: $:^{12,25,26}$

$$
\begin{gathered}
\mathrm{TiOH}+\mathrm{H}^{+} \leftrightarrow \mathrm{TiOH}_{2}^{+}\left(\mathrm{pH}<\mathrm{pH}_{\mathrm{pzc}}\right) \\
\mathrm{TiOH}+\mathrm{OH}^{-} \leftrightarrow \mathrm{TiO}^{-}+\mathrm{H}_{2} \mathrm{O}\left(\mathrm{pH}>\mathrm{pH}_{\mathrm{pzc}}\right)
\end{gathered}
$$



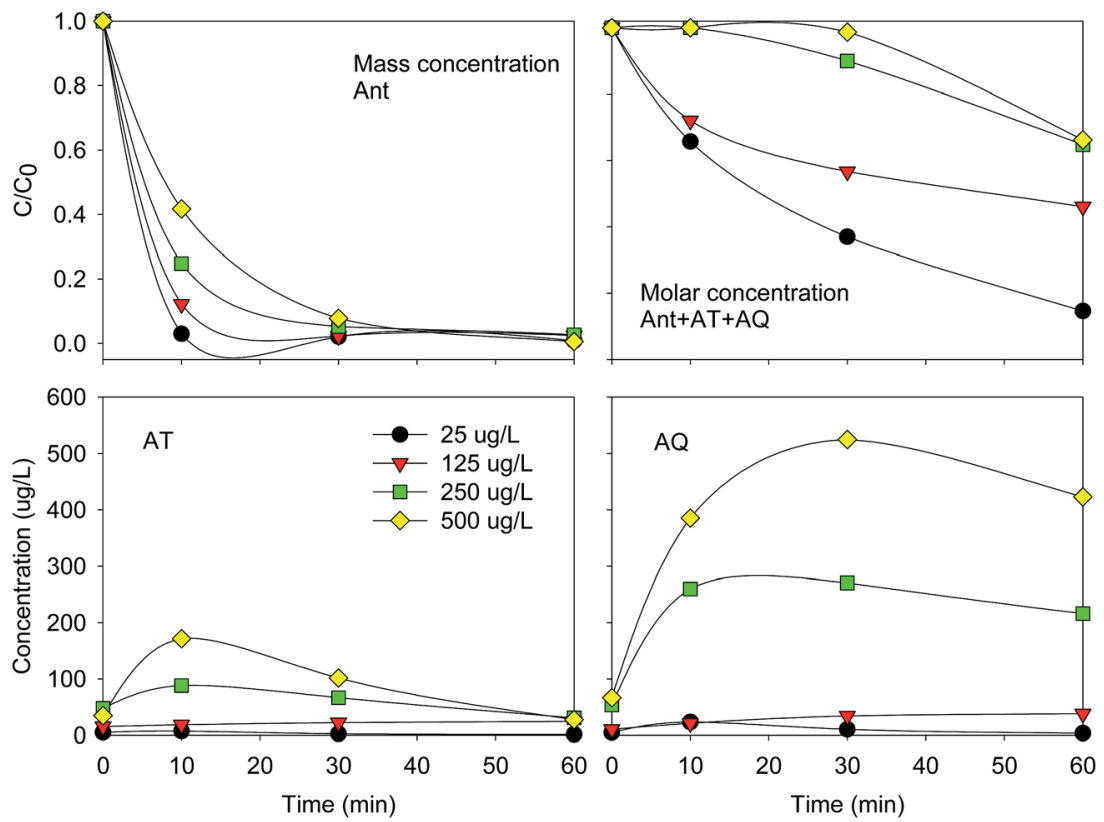

Fig. 4 Variation of Ant and $\Sigma A n t+A T+A Q$ elimination efficiency, AT and AQ concentration at different Ant initial concentrations. Conditions: $E=1.0 \mathrm{~V} ; \mathrm{pH}=2.0$.

Thus, the charge on the surface is positive at $\mathrm{pH}$ less than 6.0, and negative at $\mathrm{pH}$ higher than 6.0. Similar result was obtained in the removal of humic acid, 4-chlorocatechol and pentachlorophenol. $22,23,27$ PEC could be influenced by $\mathrm{pH}$ in many ways, including (1) the variation of $\mathrm{TiO}_{2}$ flat-band potential; (2) the changes of adsorption ability of the compounds on the $\mathrm{TiO}_{2}$ surface; (3) the competition of water or $\mathrm{OH}^{-}$oxidation with other reactants able to form powerful oxidants under light irradiation. ${ }^{24,28}$ In this study, the reason for the higher elimination efficiency of Ant at a lower $\mathrm{pH}$ value might be related to the adsorption ability of the $\mathrm{TiO}_{2}$ surface. Ant containing the rich electron group was prone to combine with $\mathrm{H}^{+}$and $\mathrm{TiOH}_{2}{ }^{+}$through the electrophilic reaction.

It could be noticed that the concentrations of AT and AQ at pH 2.0 increased in the initial $10 \mathrm{~min}$, higher than those at $\mathrm{pH}$ 8.5, then decreased from 10 to $60 \mathrm{~min}$, and finally similar to those at $\mathrm{pH}$ 8.5. As a result, the elimination efficiency of Ant + $\mathrm{AT}+\mathrm{AQ}$ at $\mathrm{pH} 2.0(E=63 \%)$ was a little higher compared with that at $\mathrm{pH} 8.5$ and $\mathrm{pH} 12.0(E=48 \%)$. The result showed that in the acidic condition, the formation of $\mathrm{AT}$ and $\mathrm{AQ}$ was much easier than in the neutral and alkaline condition. The reactivity of position 9 and 10 of Ant was the highest due to the highest electron cloud density compared with other positions. Therefore, more AT and AQ will be formed during the reaction. Additionally, the elimination of AT and AQ at $\mathrm{pH} 2.0$ was also much easier. The carbonyl could be nucleophilic addition reacted with $\mathrm{H}^{+}$in the acid condition, resulting to an easier elimination of AT and AQ.

3.2.3 Initial concentration effect. Due to that the elimination efficiencies were the highest at $\mathrm{pH} 2.0$, the influence of the initial concentrations was performed at $\mathrm{pH} 2.0$ and a bias potential $1.0 \mathrm{~V}$. The elimination rate $(k$ ranged from 0.3516 to
$0.0869 \mathrm{~min}^{-1}$ ) of Ant decreased as the increasing of the initial concentration $\left(C_{0}\right.$ ranged from 25 to $\left.500 \mu \mathrm{g} \mathrm{L}^{-1}\right)$ (Fig. 4 and Table 1). The finial elimination efficiencies were $97-99 \%$ at the initial concentration from 25 to $500 \mu \mathrm{g} \mathrm{L} \mathrm{L}^{-1}$. Similar result was obtained in previous studies, probably because the concentration increased in the solution, the available active sites on the surface of the electrode were competitive by Ant and the transformation intermediates. ${ }^{14}$

The elimination efficiencies of Ant $+\mathrm{AT}+\mathrm{AQ}$ were also lower with a higher initial Ant concentration. The formation concentrations of AT and AQ increased with the increasing initial concentration of Ant. The Ant $+\mathrm{AT}+\mathrm{AQ}$ did not vary much in the initial $10 \mathrm{~min}$ at the initial concentration of $250 \mu \mathrm{g} \mathrm{L} \mathrm{L}^{-1}$, and in the initial $20 \mathrm{~min}$ at the initial concentration of $500 \mu \mathrm{g} \mathrm{L}^{-1}$. Correspondingly, at the initial concentrations of $250 \mu \mathrm{g} \mathrm{\textrm {L } ^ { - 1 }}$ and $500 \mu \mathrm{g} \mathrm{L}^{-1}$, the concentrations of AT and AQ increased firstly and then decreased. The elimination of AT and AQ might be influenced by the photolysis process, during which the compounds

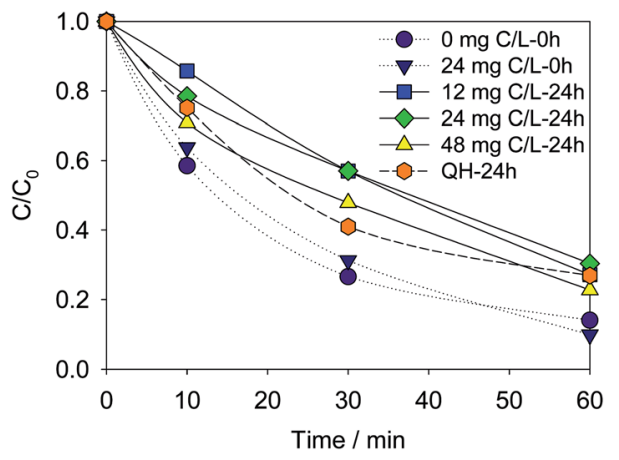

Fig. 5 Influence of humic acid on the elimination of Ant. Conditions: $C_{\text {o(Ant) }}=125 \mu \mathrm{g} \mathrm{L}^{-1}$ in UPW; $E=1.0 \mathrm{~V} ; \mathrm{pH}=8.5$. 


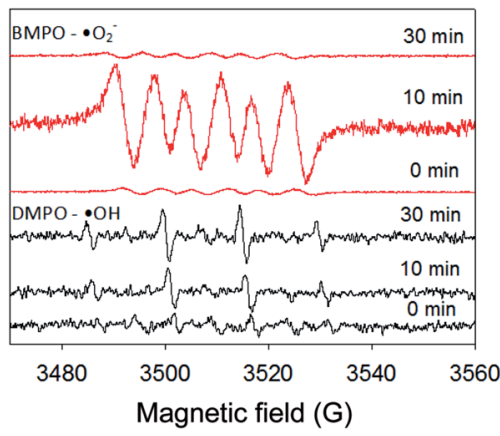

Fig. 6 Comparison of ESR at 0, 10, 30 min in PEC system.

with higher concentrations probably absorb more light, resulting to an easier conversion. ${ }^{29}$

3.2.4 Humic acid effect. Humic acid is prevalent in the water environment. The co-existence of the humic acid with the target contaminants might influence the elimination of the contaminants. ${ }^{5}$ We compared the contact times of humic acid and Ant with different humic acid concentrations, which was calculated based on the carbon concentrations (mg C/L) (Fig. 5). The elimination efficiency of Ant with $24 \mathrm{mg} \mathrm{C} / \mathrm{L}$ humic acid contacted $0 \mathrm{~h}$ before experiment was relatively similar to Ant without humic acid (90\% and $86 \%$, respectively). The elimination efficiency of Ant with 12, 24 and $48 \mathrm{mg} \mathrm{C} / \mathrm{L}$ humic acid contacted $24 \mathrm{~h}$ before experiment was also similar (73\%, 70\% and $77 \%$, respectively). The results indicated that the concentration of humic acid did not significantly influence the elimination of Ant. Therefore, the degradation of humic acid did not compete with Ant in the PEC elimination process. Besides, the solar screening by humic acid did not affect the elimination of Ant. Furthermore, it was reported that the reactive oxygen species might be formed through the solar irradiation of humic acid. ${ }^{30}$ However, the result in this study did not show the effect of the reactive oxygen species.

The elimination efficiencies of Ant contacted with the same concentration of humic acid for the different time ( 0 and $24 \mathrm{~h}$ ) before experiment were different. The elimination efficiency of Ant contacted with $24 \mathrm{mg} \mathrm{C} / \mathrm{L}$ humic acid for $24 \mathrm{~h}$ (70\%) was lower than $0 \mathrm{~h}(90 \%)$. As a result, Ant was probably combined with the humic acid. The elimination of Ant would be influenced by the degradation of the humic acid. Therefore, the elimination efficiency of Ant reduced when being contacted with humic acid for $24 \mathrm{~h}$.

A real water sample was used to determine the influence of DOM on the elimination of Ant. Secondary effluent from a municipal wastewater treatment plant $(\mathrm{QH})$ was spiked with Ant for $24 \mathrm{~h}$. The concentration of TOC was $7.6 \mathrm{mg} \mathrm{L}^{-1}$. Though the TOC was lower than humic acid added in this study, the existence of DOM in real water could also decrease the elimination efficiency of Ant as the humic acid (73\%). However, the elimination rate was different from the humic acid, possibly indicating a different composition of DOM to humic acid.

\subsection{Oxidation mechanism}

ESR technique was used for the identification of free radical related to the elimination of Ant. As shown in Fig. $6,{ }^{\circ} \mathrm{O}_{2}{ }^{-}$signal was significant at $10 \mathrm{~min}$, but weak at 0 and $30 \mathrm{~min}$. $\mathrm{OH}$ signal increased from 0 to $30 \mathrm{~min}$. The result indicated that both the ${ }^{\circ} \mathrm{O}_{2}{ }^{-}$and ${ }^{\circ} \mathrm{OH}$ were generated in the PEC system. The elimination rate of Ant increased in the initial $15 \mathrm{~min}$ and decreased from $15 \mathrm{~min}$ to $60 \mathrm{~min}$, suggesting that ${ }^{\circ} \mathrm{O}_{2}{ }^{-}$might be more effective than ${ }^{\circ} \mathrm{OH}$ for the elimination of Ant.

To further investigate the effect of ${ }^{\circ} \mathrm{O}_{2}{ }^{-}$and ${ }^{\circ} \mathrm{OH}$ on the elimination of Ant, different quenchers were added to the system (Fig. 7). The elimination efficiency of Ant significantly decreased after benzoquinone (BQ) was added, which was the
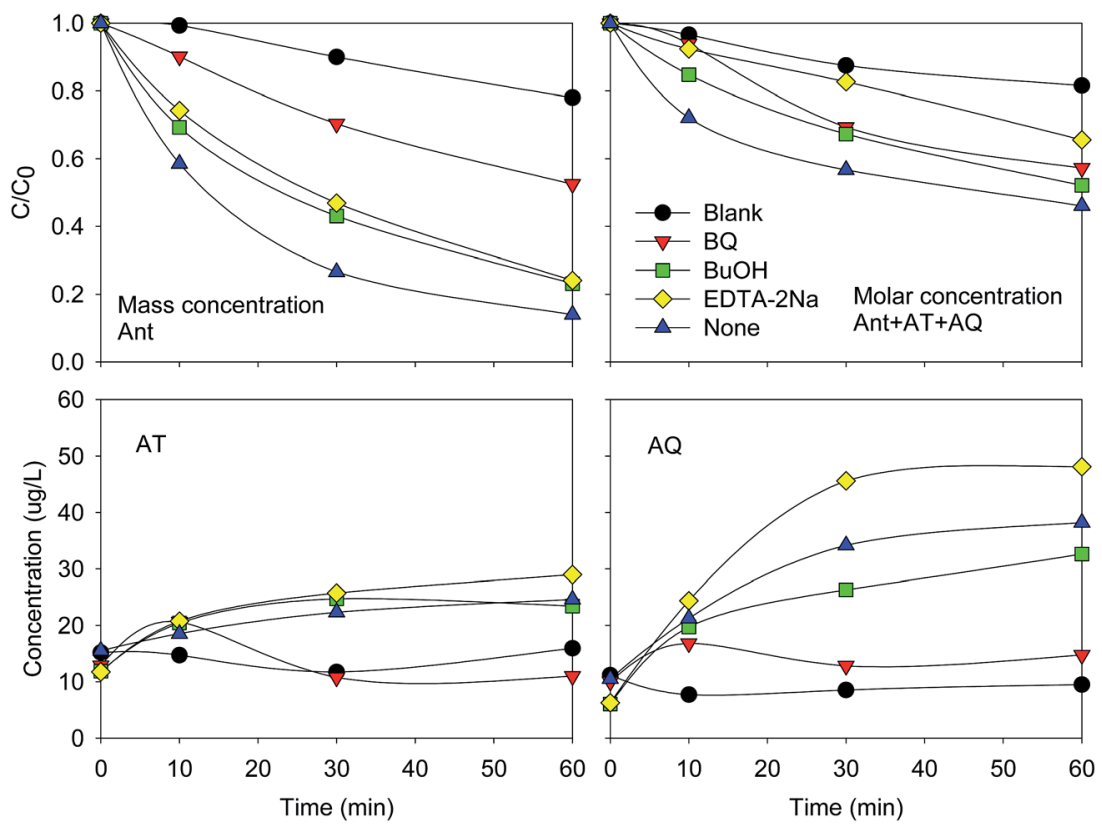

Fig. 7 Effect of different quenchers to the elimination of Ant and $\Sigma A$ nt $+A T+A Q$, and the formation of $A T$ and $A Q$. 
quencher of ${ }^{\circ} \mathrm{O}_{2}{ }^{-}$, indicating again that ${ }^{\circ} \mathrm{O}_{2}{ }^{-}$was the effective radical for the elimination of Ant. The adding of tert-butyl alcohol $(\mathrm{BuOH})$ and EDTA-2Na, the quencher of ${ }^{\circ} \mathrm{OH}$ and photogenerated holes respectively, was slightly reduce the elimination of Ant.

It was also noticed that AT and AQ were nearly not detected when $\mathrm{BQ}$ was added, indicating that ${ }^{\circ} \mathrm{O}_{2}{ }^{-}$was the effective radical transform Ant to AT and AQ. This result was consistent with a previous study that Ant was firstly transformed to AT and AQ (Fig. S2 $\dagger$ ). ${ }^{5}$ The concentrations of AT were similar when $\mathrm{BuOH}$ and EDTA-2Na were used to the non-using of the quenchers. The concentration of $\mathrm{AQ}$ was a little lower when $\mathrm{BuOH}$ was added, indicating that ${ }^{\circ} \mathrm{OH}$ was also effective for the transformation of Ant to AQ. However, the concentration of AQ was higher when EDTA-2Na was added, suggesting that the absence of photogenerated holes might facilitate the generation of AQ. Therefore, the photogenerated holes might prevent the formation of $\mathrm{AQ}$.

\subsection{Estimation of energy consumption}

In order to figure out the energy saving using the electricity combined with solar light irradiation to eliminate a typical $\mathrm{PAH}$, the energy consumption for treating $200 \mathrm{~mL}$ water containing $125 \mu \mathrm{g} \mathrm{L}^{-1}$ Ant was calculated in the PEC with solar light and PC with UV light system. In the PEC-solar system of this study, the optimal bias was $1.0 \mathrm{~V}$. The corresponding current ranged from 2.8 to $3.1 \mathrm{~mA}$, and an average of $3.0 \mathrm{~mA}$ was used for estimation. The reaction time was $60 \mathrm{~min}$. Thus, the power consumption was $3.0 \times 10^{-6} \mathrm{~kW}$ h. The energy consumption of the Xe lamp was not added because this energy could be compensated when using the real solar energy. In the PC-UV system in our previous study, ${ }^{31}$ the power of the UV light was $15 \mathrm{~W}$. The reaction time was $10 \mathrm{~min}$. Thus, the power consumption was $2.5 \times 10^{-3} \mathrm{~kW}$ h. Therefore, the PEC-solar system could save much energy compared to the PC-UV system on the aspect of Ant elimination.

\section{Conclusions}

The transformation intermediates of Ant including AT and AQ were detected during the PEC process. The eliminations of Ant and Ant $+\mathrm{AT}+\mathrm{AQ}$ were enhanced by PEC compared with the DP, PC and EO process. However, the eliminations of AT and AQ were hardly observed in $60 \mathrm{~min}$. Therefore, transformation intermediates should be considered during the elimination process of organic contaminants. The best elimination efficiencies of Ant and Ant $+\mathrm{AT}+\mathrm{AQ}$ were achieved at a bias potential of $1.0 \mathrm{~V}$. The elimination efficiency of Ant was higher in acid solution than that in the neutral and alkaline solution. The elimination efficiencies of Ant and Ant + AT + AQ increased with the decreasing of the Ant initial concentration. The contact time of humic acid and Ant was greatly influence the elimination of Ant rather than the concentration of humic acid. The active species ${ }^{\circ} \mathrm{OH}$ and especially ${ }^{\circ} \mathrm{O}_{2}{ }^{-}$were mainly responsible for the elimination of Ant. Furthermore, based on the estimation of the energy consumption, $\mathrm{TiO}_{2}$ nanotube with solar light irradiation and a bias potential could save much energy compared with the UV light on the aspect of Ant elimination.

\section{Conflicts of interest}

There are no conflicts to declare.

\section{Acknowledgements}

This work was supported by National Natural Science Foundation of China (Grant No. 51508552 and 51438011).

\section{References}

1 O. T. Woo, W. K. Chung, K. H. Wong, A. T. Chow and P. K. Wong, J. Hazard. Mater., 2009, 168, 1192-1199.

2 M. Qiao, W. X. Qi, H. J. Liu and J. H. Qu, Water Res., 2014, 52, 11-19.

3 M. Qiao, W. X. Qi, H. J. Liu and J. H. Qu, Sci. Total Environ., 2014, 481, 178-185.

4 B. Pal and M. Sharon, J. Mol. Catal. A: Chem., 2000, 160, 453460.

5 S. Sanches, C. Leitao, A. Penetra, V. V. Cardoso, E. Ferreira, M. J. Benoliel, M. T. B. Crespo and V. J. Pereira, J. Hazard. Mater., 2011, 192, 1458-1465.

6 C. B. Liu, Y. B. Ding, W. Q. Wu and Y. R. Teng, Chem. Eng. J., 2016, 306, 22-30.

7 T. E. Rosser, M. A. Gross, Y. H. Lai and E. Reisner, Chem. Sci., 2016, 7, 4024-4035.

8 Z. H. Wang, G. J. Zou, W. Wang, Z. C. Tang, Y. P. Bi and X. L. Wang, J. Power Sources, 2017, 343, 94-102.

$9 \mathrm{~J}$. Wang and W. D. Zhang, Electrochim. Acta, 2012, 71, 10-16.

10 P. A. Christensen, T. P. Curtis, T. A. Egerton, S. A. M. Kosa and J. R. Tinlin, Appl. Catal., B, 2003, 41, 371-386.

11 J. C. Cardoso, T. M. Lizier and M. V. B. Zanoni, Appl. Catal., B, 2010, 99, 96-102.

12 Y. Z. Zhang, X. Y. Xiong, Y. Han, X. H. Zhang, F. Shen, S. H. Deng, H. Xiao, X. Y. Yang, G. Yang and H. Peng, Chemosphere, 2012, 88, 145-154.

13 I. K. Konstantinou and T. A. Albanis, Appl. Catal., B, 2004, 49, 1-14.

14 Z. Frontistis, V. M. Daskalaki, A. Katsaounis, I. Poulios and D. Mantzavinos, Water Res., 2011, 45, 2996-3004.

15 J. H. Park, T. W. Lee and M. G. Kang, Chem. Commun., 2008, 2867-2869.

16 S. G. Yang, Y. Z. Liu and C. Sun, Appl. Catal., A, 2006, 301, 284-291.

17 N. Wang, X. Y. Li, Y. X. Wang, X. Quan and G. H. Chen, Chem. Eng. J., 2009, 146, 30-35.

18 X. Nie, G. Y. Li, M. H. Gao, H. W. Sun, X. L. Liu, H. J. Zhao, P. K. Wong and T. C. An, Appl. Catal., B, 2014, 147, 562-570.

19 X. Zhao, J. J. Zhang and J. H. Qu, Electrochim. Acta, 2015, 180, 129-137.

20 X. Zhao, T. G. Xu, W. Q. Yao, C. Zhang and Y. F. Zhu, Appl. Catal., B, 2007, 72, 92-97.

21 X. Zhao and Y. F. Zhu, Environ. Sci. Technol., 2006, 40, 33673372 . 
22 H. Selcuk and M. Bekbolet, Chemosphere, 2008, 73, 854-858. 23 X. Quan, X. L. Ruan, H. M. Zhao, S. Chen and Y. Z. Zhao, Environ. Pollut., 2007, 147, 409-414.

24 A. Rubio-Clemente, R. A. Torres-Palma and G. A. Penuela, Sci. Total Environ., 2014, 478, 201-225.

25 D. D. Dionysiou, M. T. Suidan, E. Bekou, I. Baudin and J. M. Laine, Appl. Catal., B, 2000, 26, 153-171.

26 S. F. Chen and Y. Z. Liu, Chemosphere, 2007, 67, 1010-1017.
27 J. M. Kesselman, N. S. Lewis and M. R. Hoffmann, Environ. Sci. Technol., 1997, 31, 2298-2302.

28 X. Quan, S. Chen, J. Su, J. Chen and G. Chen, Sep. Purif. Technol., 2004, 34, 73-79.

29 J. S. Miller and D. Olejnik, Water Res., 2001, 35, 233-243.

$30 \mathrm{~J}$. Wenk, U. von Gunten and S. Canonica, Environ. Sci. Technol., 2011, 45, 1334-1340.

31 B. Liu, L. Wang, M. Qiao, T. Guo, Y. Wang, W. Cao and X. Zhao, Res. Environ. Sci., 2017, 30, 322-328. 